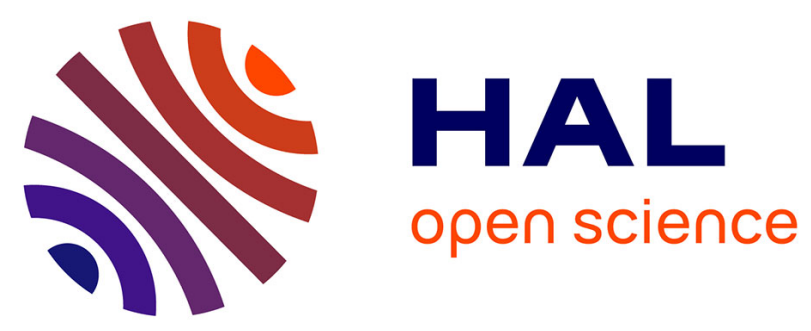

\title{
A multi-dimensional evaluation of craving and impulsivity among people admitted for alcohol-related problems in emergency department
}

Valentin Flaudias, Frederique Teisseidre, Ingrid de Chazeron, Maryline Chalmeton, Celian Bertin, Marie Izaute, Nadia Chakroun-Baggioni, Bruno Pereira, Georges Brousse, Pierre Maurage

\section{To cite this version:}

Valentin Flaudias, Frederique Teisseidre, Ingrid de Chazeron, Maryline Chalmeton, Celian Bertin, et al.. A multi-dimensional evaluation of craving and impulsivity among people admitted for alcohol-related problems in emergency department. Psychiatry Research, 2019, 272, pp.569-571. 10.1016/j.psychres.2018.12.118 . hal-01982438

\section{HAL Id: hal-01982438 \\ https://hal.science/hal-01982438}

Submitted on 13 Oct 2021

HAL is a multi-disciplinary open access archive for the deposit and dissemination of scientific research documents, whether they are published or not. The documents may come from teaching and research institutions in France or abroad, or from public or private research centers.
L'archive ouverte pluridisciplinaire HAL, est destinée au dépôt et à la diffusion de documents scientifiques de niveau recherche, publiés ou non, émanant des établissements d'enseignement et de recherche français ou étrangers, des laboratoires publics ou privés. 


\section{A multi-dimensional evaluation of craving and impulsivity among people admitted for alcohol-related problems in emergency department}

Valentin Flaudias $^{\mathrm{a}^{*}}$, Frederique Teisseidre ${ }^{\mathrm{b}}$, Ingrid De Chazeron ${ }^{\mathrm{a}}$, Maryline Chalmeton ${ }^{\mathrm{a}}$, Celian Bertin $^{\mathrm{c}}$, Marie Izaute ${ }^{\mathrm{b}}$, Nadia Chakroun-Baggioni ${ }^{\mathrm{b}}$, Bruno Pereira ${ }^{\mathrm{d}}$, Georges Brousse $^{\mathrm{a}}$, Pierre Maurage ${ }^{\mathrm{e}}$.

${ }^{a}$ Université Clermont Auvergne, EA NPsy-Sydo, BP 10448, F-63000 Clermont-Ferrand, France. CHU Clermont-Ferrand, Pôle Psychiatrie B, F-63001 Clermont-Ferrand, France.

${ }^{\mathrm{b}}$ Université Clermont Auvergne, CNRS UMR 6024, LAPSCO, F-63000 Clermont-Ferrand, France

${ }^{\mathrm{c}}$ Université Clermont Auvergne, CHU Clermont-Ferrand, Inserm, Neuro-Dol, Service de

Pharmacologie médicale, Centres Addictovigilance et Pharmacovigilance, Centre Evaluation et Traitement de la Douleur, F-63001, Clermont-Ferrand, France

${ }^{d}$ University hospital Clermont-Ferrand, biostatistics unit (DRCI), Clermont-Ferrand, France.

${ }^{\mathrm{e}}$ Laboratory for Experimental Psychopathology, Psychological Sciences Research Institute, Université catholique de Louvain, Louvain-la-Neuve, Belgium.

*Corresponding author: Valentin Flaudias, PhD, Pôle Psychiatrie B, 58 Rue Montalembert, F63000 Clermont-Ferrand, France. vflaudias@ @hu-clermontferrand.fr , +33 473752072

Number of words: 1689 


\begin{abstract}
Craving and impulsivity are key psychological dimensions involved in the development and maintenance of severe alcohol-use disorders. This study proposes an integrative evaluation of craving (Visual Analogue Scale, VAS and Obsessive Compulsive Drinking Scale, OCDS) and impulsivity (UPPS Scale and Barratt Impulsiveness Scale) among patients admitted in emergency department for alcohol misuse. Ninety-eight patients were included. Regression analyses showed that the scores obtained at the compulsive subscale of the OCDS, at the VAS and at the Urgency subscale of impulsivity constitute the main predictors of the severity of alcohol-use disorders (indexed by the AUDIT). These results suggest that specific subdimensions of craving and impulsivity may play a critical and joint role in the maintenance of excessive alcohol consumption.
\end{abstract}

Keywords. Alcohol use disorders; craving; impulsivity; emergency department. 


\section{Introduction}

Craving and impulsivity are considered as key psychological dimensions involved in the emergence and development of alcohol-use disorders. Craving is an intense subjective desire and urge towards alcohol, promoting compulsive consumption (Tiffany, 1990). Impulsivity covers a wide-range of poorly planned and excessive behaviors often leading to negative consequences (Moeller et al., 2001), among which uncontrolled substance consumption (Jentsch et al., 2014). These two factors, which have also been suggested as predictors of relapse following treatment (Joos et al., 2013), are conceptualized as multidimensional: First, Anton (1999) distinguished obsessive (i.e. intrusive thoughts or mental images) and compulsive (i.e. ritualized drinking behaviors) dimensions of craving, classically measured using the Obsessive Compulsive Drinking Scale [OCDS (Anton et al., 1995)]. Second, two main multidimensional impulsivity models are currently dominant in addictive states, namely (1) the UPPS (Whiteside and Lynam, 2001), distinguishing four impulsivity factors: urgency (the tendency to produce rash behavioral responses when facing intense positive or negative emotional states), lack of perseverance (the difficulty to maintain one's attentional focus on a task which might be hard, long or boring), lack of premeditation (the difficulty to plan one's behaviors or to think about the consequences of an action before performing it), sensation seeking (the propensity to look for thrilling and unconventional life experiences, despite their riskiness); and (2) the Barratt Impulsiveness Scale (BIS, Patton et al., 1995), considering three impulsivity factors: Attentional impulsivity (the inability to focus attentional resources on a task), Motor impulsivity (the production of behaviors without preliminary thinking), and non-planning impulsivity (the lack of consideration of future consequences of one's behavior).

While these two concepts have been widely explored in alcohol-use disorders, several questions remain, as craving and impulsivity have: (1) been mostly explored separately, their 
interactions not being fully understood; (2) centrally been studied in patients presenting severe alcohol-use disorders or among healthy social drinkers. Their respective roles on other types of population presenting alcohol-related disorders remain to be determined. In particular, patients admitted on emergency department for alcohol misuse constitute a population of interest, as they have specific characteristics: while they are most often seeking help in link with intense acute consumption (te Wildt et al., 2006), 75\% of them will later be admitted in detoxification therapy for chronic alcohol-related disorders (Djenati et al., 2008), highlighting the particularly stage of alcohol-use disorders they are confronted with (i.e. a problematic use of alcohol, but not yet intense enough to lead them towards detoxification therapy). However, craving and impulsivity have not yet been measured in this population.

We propose an integrative and joint evaluation of craving and impulsivity among patients admitted in emergency department, using a multimodal perspective including multiple impulsivity (UPPS, BIS) and craving [OCDS, craving visual analogue scale (VAS)] evaluations. We hypothesized that, beyond high impulsivity and craving, a strong link will be observed between the severity of alcohol-use disorders on the one hand, and compulsive craving, sensation seeking and non-planning impulsiveness on the other hand, these dimensions being the most related to the unplanned and dangerous behaviors observed in this population (Cherpitel and Ye, 2009; Zerhouni et al., 2013).

\section{Methods}

\subsection{Participants}

The study was conducted in the University Hospital "Gabriel Montpied" (Clermont-Ferrand, France) between April and May 2012, and approved by the Ethical Committee of the Hospital. The inclusion criterion was to be admitted to the emergency department for alcohol misuse. 178 patients fulfilled this criterion, but 78 were excluded because they refused to take 
part in the study or presented psychiatric/neurological symptoms, and two were excluded because of their age (higher than 90 years old). The final sample thus comprised 98 patients. Inclusion was conducted during the admission day, after the blood alcohol level was back to zero, when the mental state of patients allowed psychological evaluation, and when there was no severe withdrawal symptoms, as assessed by a senior medical doctor.

\subsection{Clinical assessments}

We used the AUDIT (Gache et al., 2005; Saunders et al., 1993) to assess the severity of alcohol-use disorders, the UPPS (Whiteside and Lynam, 2001; Van der Linden et al., 2006) and the Barratt Impulsiveness Scale [BIS-11, (Patton et al., 1995)] to assess impulsivity, and the OCDS (Anton, Moak, \& Latham, 1995; Chignon et al., 1997) and a single-item VAS to assess craving. The VAS instruction was "Indicate, on the following scale, the usual intensity of your desire for alcohol when it occurs, by putting a mark on the line going from "very weak desire" to "irresistible desire". The more your mark is on the right, the more intense is your desire". The VAS was thus a continuous measure as the mark could be placed at any level, and was then recoded as a 0 to 10 score $(M=5.01 ; S D=3.05,6$ patients reporting a score of 0,8 patients reporting a score of 10; one missing data;). All these assessments were self-reported questionnaires, and Cronbach's $\alpha$ are indicated in Table 1.

\subsection{Procedure}

Before starting the experiment, each patient was informed about the aims of the study. Patients were free to participate and did not receive any compensation. The study was conducted individually, starting with the self-administered questionnaires followed by the AUDIT interview, carried out by two trained psychologists. The total procedure lasted one hour on average.

\section{Results}


Patients were between 18 and 65 years old $\left(M_{a g e}=42.26 ; S D=12.89\right)$, and the sample consisted of 37 women $\left(M_{a g e}=42.7 ; S D=14.85\right)$ and 61 men $(M a g=41.98 ; S D=11.67)$. The mean AUDIT score was $23.66(S D=8.29)$ : A low dependence risk (score lower than 8 ) was present in $6 \%$ of the patients, 9\% were hazardous drinkers (score between 9 and 15), 14\% were harmful drinkers (score between 16 and 19), and $69 \%$ presented a high dependence risk (score higher than 19) (Babor et al., 2001).

Spearman's correlations analyses showed that all sub-dimensions of craving were correlated with the severity of alcohol-use disorders. All impulsivity sub-dimensions were correlated with the severity of alcohol-use disorders, except the lack of premeditation $(p=0.781)$ and the lack of perseverance $(p=0.056)$.

Linear multiple hierarchical regression with all scores (normalized through log transformation) was conducted. The first step explored AUDIT scores as dependent variable and age and sex as predictive factors, and showed no significant effect. The second step added impulsivity (BIS/UPPS subscales) and craving (VAS/OCDS sub-scores) as predictive factors, showing that the only significant predictive factors for the AUDIT $\left(R^{2}=0.701, F(12,85)\right.$ $=16,627, p<0.001)$ were the OCDS compulsive subscale $(p<0.001)$, the craving VAS $(p=0.042)$ and the urgency dimension of the UPPS (Table 1).

\section{<Insert Table 1 here >}

Receiver operating characteristic (ROC) curve analysis indicated which VAS score best predicted harmful consumption measured by the AUDIT (i.e., score higher than 16). A craving threshold score of three (on a VAS ranging from 0 to 10) optimized sensitivity (0.817) and specificity (0.800). The area under the curve was 0.876 and the asymptotic significance was lower than 9.001 [95\% CI $=0.790,0.961]$.

\section{Discussion}


The primary aim of this study was to explore the role played by two major factors related to the severity of alcohol-use disorders (craving and impulsivity) in a population of patients admitted to emergency department for alcohol-related problems. Our results first confirmed that craving is an important factor linked with the severity of alcohol-use disorders in this population, particularly for its compulsive dimension which is more strongly involved than the obsessive one (more centrally involved in relapse and disease persistence, Anton et al., 1995).

We also observed an important predictive effect of subjective craving, as assessed by the VAS, on alcohol-related disorder. This result complements previous ones, as this scale reflects the global subjective feeling regarding craving. Indeed, craving can be an unconscious process (Sayette, 2016) difficult to target in short medical care perspective, but the VAS offers a rapid evaluation of self-reported conscious craving. The ROC analysis moreover showed that a score above three on this scale, indicating moderate craving, constitutes an interesting threshold to detect patients presenting harmful drinking. Despite this potential clinical usefulness of the VAS scale to perform a quick-scan of patients regarding their craving intensity and alcohol-related disorders, it should be underlined that: (1) as the VAS is based on a one-item scale, it might lead to erroneous information and clinical decision when this item is misinterpreted by the patients, and it obviously do not replace an in-depth evaluation of the multidimensional concept of craving; (2) the threshold determined here could be strongly influenced by the population included in the study, and might thus not be generalizable to other populations (e.g., patients presenting more severe alcohol-use disorders) or contexts (e.g., other clinical settings or regions/countries).

Our results did not show any strong effect of impulsivity factors (UPPS, BIS) on alcohol-use severity when craving was included in the regression analysis. The only significant effect concerned the urgency dimension of the UPPS, which is in line with 
previous studies (Lannoy et al., 2017). As impulsivity is strongly involved in the emergence of excessive alcohol consumption (e.g., binge drinking, Cyders et al., 2009), it could centrally be a predictor of problematic use. Our study suggests that subjective craving and compulsive behaviors are more linked with alcohol-related severity than impulsivity, which highlights the urgent need to take craving evolution into account when exploring the developmental aspects of addictive states and the specificities of each population. Moreover, the relationship between craving and urgency dimensions of impulsivity need more exploration: we exclusively used self-reported questionnaires and these results should be further explored through experimental tasks. Moreover, the correlational nature of this study, as well as the limits related to the AUDIT (e.g., grouping situational and long-term alcohol-consumption items in a global score) reduce the strengths of the conclusions that can be drawn.

As a whole, this study proposed to determine how impulsivity and craving measures can predict excessive alcohol consumption in an under-explored high-risk population admitted in emergency department. Results showed the important relationship between craving (particularly its subjective and compulsive aspects) and alcohol-use severity. While these results should be replicated on larger and multicentric samples, they suggest a potential interest of using a simple VAS craving assessment in clinical settings to obtain a fast while preliminary evaluation of this key psychological component. 
Financial support. This work was support by a grant from the Mission Interministérielle de Lutte Contre les Drogues Et les Conduites Addictives (MILDECA) and with a grant "Bourse de mobilité jeune chercheur» proposed by the Cancéropole Lyon Auvergne Rhône-Alpes (CLARA). PM (Senior Research Associate) is funded by the Belgian Fund for Scientific Research (F.R.S.-FNRS, Belgium)

Conflict of interest. None 


\section{References}

Anton, R.F., 1999. What is craving?: Models and implications for treatment. Alcohol Res. Health 23, 165-173.

Anton, R.F., Moak, D.H., Latham, P., 1995. The Obsessive Compulsive Drinking Scale: a self-rated instrument for the quantification of thoughts about alcohol and drinking behavior. Alcohol. Clin. Exp. Res. 19, 92-99.

Babor, T.F., Higgins-Biddle, Saunders, J.B., Monteiro, M.G., World Health Organization, 2001. AUDIT: the alcohol use disorders identification test: guidelines for use in primary health care.

Cherpitel, C.J., Ye, Y., 2009. Alcohol and Injury in the United States General Population: A Risk Function Analysis from the 2005 National Alcohol Survey. Am. J. Addict. 18, 29-35. https://doi.org/10.1080/10550490802544045

Chignon, J., Jacquesy, L., Mennad, M., Terki, A., Huttin, F., Martin, P., Chabannes, J., 1997. [Selfassessment questionnaire of alcoholic craving (ECCA Questionnaire: Behavior and Cognition in Relation to Alcohol: French translation and validation of the Obsessive-Compulsive Drinking Scale]. L'Encephale 24, 426-434.

Cyders, M.A., Flory, K., Rainer, S., Smith, G.T., 2009. The Role of Personality Dispositions to Risky Behavior in Predicting First Year College Drinking. Addict. Abingdon Engl. 104, 193-202. https://doi.org/10.1111/j.1360-0443.2008.02434.X

Djenati, Z., Bardoux, A., Becker, T., Youssef, N., Alarcon, P., Gower-Rousseau, C., Paradis, P., 2008. Prévalence de l'abus d'alcool chez des patients admis aux Urgences. Alcoologie Addictologie 30, 181-185.

Gache, P., Michaud, P., Landry, U., Accietto, C., Arfaoui, S., Wenger, O., Daeppen, J.-B., 2005. The Alcohol Use Disorders Identification Test (AUDIT) as a screening tool for excessive drinking in primary care: reliability and validity of a French version. Alcohol. Clin. Exp. Res. 29, 20012007.

Jentsch, J.D., Ashenhurst, J.R., Cervantes, M.C., Groman, S.M., James, A.S., Pennington, Z.T., 2014. Dissecting impulsivity and its relationships to drug addictions. Ann. N. Y. Acad. Sci. 1327, 126. https://doi.org/10.1111/nyas.12388

Joos, L., Goudriaan, A.E., Schmaal, L., De Witte, N.A.J., Van den Brink, W., Sabbe, B.G.C., Dom, G., 2013. The relationship between impulsivity and craving in alcohol dependent patients. Psychopharmacology (Berl.) 226, 273-283. https://doi.org/10.1007/s00213-012-2905-8

Lannoy, S., Billieux, J., Poncin, M., Maurage, P., 2017. Binging at the campus: motivations and impulsivity influence binge drinking profiles in university students. Psychiatry Res. https://doi.org/10.1016/j.psychres.2017.01.068

Moeller, F.G., Barratt, E.S., Dougherty, D.M., Schmitz, J.M., Swann, A.C., 2001. Psychiatric aspects of impulsivity. Am. J. Psychiatry 158, 1783-1793.

Patton, J.H., Stanford, M.S., Barratt, E.S., 1995. Factor structure of the Barratt impulsiveness scale. J. Clin. Psychol. 51, 768-774.

Saunders, J.B., Aasland, O.G., Babor, T.F., de la Fuente, J.R., Grant, M., 1993. Development of the Alcohol Use Disorders Identification Test (AUDIT): WHO Collaborative Project on Early Detection of Persons with Harmful Alcohol Consumption--II. Addict. Abingdon Engl. 88, 791804.

Sayette, M.A., 2016. The Role of Craving in Substance Use Disorders: Theoretical and Methodological Issues. Annu. Rev. Clin. Psychol. 12, 407-433. https://doi.org/10.1146/annurev-clinpsy021815-093351

te Wildt, B.T., Andreis, C., Auffahrt, I., Tettenborn, C., Kropp, S., Ohlmeier, M., 2006. Alcohol related conditions represent a major psychiatric problem in emergency departments. Emerg. Med. J. EMJ 23, 428-430. https://doi.org/10.1136/emj.2005.028415

Tiffany, S.T., 1990. A cognitive model of drug urges and drug-use behavior: role of automatic and nonautomatic processes. Psychol. Rev. 97, 147-168. 
Van der Linden, M., d'Acremont, M., Zermatten, A.N., Jermann, F., Lari, F., Willems, S., Juillerat, A.C., Bechara, A., 2006. A French adaptation of the UPPS Impulsive Behavior Scale - Confirmatory factor analysis in a sample of undergraduate students. Eur. J. Psychol. Assess. 22, 38-42. https://doi.org/10.1027/1015-5759.22.1.38

Whiteside, S.P., Lynam, D.R., 2001. The Five Factor Model and impulsivity: using a structural model of personality to understand impulsivity. Personal. Individ. Differ. 30, 669-689. https://doi.org/10.1016/S0191-8869(00)00064-7

Zerhouni, O., Bègue, L., Brousse, G., Carpentier, F., Dematteis, M., Pennel, L., Swendsen, J., Cherpitel, C., 2013. Alcohol and Violence in the Emergency Room: A Review and Perspectives from Psychological and Social Sciences. Int. J. Environ. Res. Public. Health 10, 4584-4606. https://doi.org/10.3390/ijerph10104584 


\section{Table}

Table 1. Multiple hierarchical regression analyses determining the predicting value of craving (measured with OCDS and VAS) and impulsivity (measured with BIS and UPPS) on alcohol-use disorder score (measured with AUDIT).

\begin{tabular}{|c|c|c|c|c|c|c|c|c|c|c|}
\hline & $\begin{array}{c}\text { Dependent } \\
\text { variable }\end{array}$ & Independent variables & $\begin{array}{c}\text { Cronbach } \\
\alpha\end{array}$ & Beta & $t$ & p-value & $95 \% I C$ & $\begin{array}{c}R^{2} \\
\text { adjusted }\end{array}$ & $F$ & $p$-value \\
\hline \multirow{2}{*}{ Step 1} & AUDIT & Age & - & -0.019 & -0.187 & 0.852 & {$\left[\begin{array}{lll}-0.004 & 0.003\end{array}\right]$} & 0.014 & 0.675 & 0.511 \\
\hline & $(\alpha=0.776)$ & Gender & - & $-0,116$ & -1.141 & 0.257 & {$\left[-0.134 \_0.036\right]$} & & & \\
\hline \multirow[t]{12}{*}{ Step 2} & AUDIT & Age & - & -0.079 & -1.109 & 0.270 & {$\left[-0.003 \_0.001\right]$} & 0.701 & 16.627 & $<0.001$ \\
\hline & & Gender & - & -0.091 & -1.467 & 0.146 & {$\left[-0.090 \_0.014\right]$} & & & \\
\hline & & BIS Attentional Impulsivity & 0.639 & 0.014 & 0.179 & 0.858 & {$[-0.282-0.338]$} & & & \\
\hline & & BIS Motor Impulsivity & 0.602 & -0.023 & -0.284 & 0.777 & {$\left[-0.443 \_0.332\right]$} & & & \\
\hline & & BIS Non-planning Impulsivity & 0.683 & 0.083 & 0.927 & 0.357 & {$\left[-0.221 \_0.606\right]$} & & & \\
\hline & & OCDS Compulsive score & 0.878 & 0.613 & 5.376 & 0.001 & {$[0.251[0.545]$} & & & \\
\hline & & OCDS Obsessive score & 0.917 & -0.045 & -0.413 & 0.681 & {$\left[-0.123 \_0.081\right]$} & & & \\
\hline & & UPPS Urgency & 0.868 & 0.164 & 2.274 & 0.025 & {$\left[0.039 \_0.579\right]$} & & & \\
\hline & & UPPS Lack of Premeditation & 0.867 & 0.109 & 1.383 & 0.170 & {$\left[-0.077 \_0.432\right]$} & & & \\
\hline & & UPPS Lack of Perseverance & 0.825 & -0.092 & -1.13 & 0.262 & {$\left[-0.449 \_0.124\right]$} & & & \\
\hline & & UPPS Sensation Seeking & 0.810 & 0.043 & 0.596 & 0.553 & {$\left[-0.163 \_0.303\right]$} & & & \\
\hline & & Visual Analogue Scale of Craving & - & 0.205 & 2.532 & 0.013 & [0.027_0.223] & & & \\
\hline
\end{tabular}

Note $:$ OCDS = Obsessive Compulsive Drinking Scale; UPPS = UPPS Impulsive Behavior Scale 